\title{
Artificial Intelligence and Modern Home Design
}

\author{
Jialu Song, Yifei Li \\ Sichuan Agricultural University
}

Keywords: Artificial intelligence; Modern home.

\begin{abstract}
With the development of economy and technology and the continuous development of scientific and technological intelligence equipment, artificial intelligence has begun to enter modern home design. Artificial intelligence can greatly reduce the daily operating time and energy cost and promotes the optimization of life quality. If we say artificial intelligence's engagement in modern home design is an irreversible trend, and the living interest of people is changed gradually by machine, intelligence emotion replaces gradually, this is perhaps a double-edged sword. The purpose of this paper is to identify the advantages of artificial intelligence application in modern home design and reflect upon its disadvantages of artificial intelligence, and look out on the prospects of the future of artificial intelligence.
\end{abstract}

\section{The concept and developments of artificial intelligence}

\subsection{Introduction}

Some people say that the 21 st century is the age of artificial intelligence. In the summer of 1956, McCarthy officially proposed the term "artificial intelligence" that lasted up to the present. Artificial intelligence has been in blossom with radiant light on the stage of the mankind and widely set foot in various fields with its on-going expansion.

\subsection{Concept}

Artificial Intelligence, or AI, is a new technical science, which is developed with the combination of many subjects. In simple terms, artificial intelligence is to endow machines with human intelligence, simulate human thinking so as to help people solve problems and to realize more advanced applications such as computer-aided human production and living.

Artificial intelligence, a branch of computer science, is considered to be one of the three most advanced technologies (Genetic engineering, Nano science and Artificial intelligence) in the $21 \mathrm{st}$ century. ${ }^{[1]}$ Artificial intelligence has achieved extremely rapid development in the past 30 years and has been widely used in many academic fields.
AI has been increasingly imbedded into people's daily life, such as: more and more well-functioned smartphones, smart watches, unmanned vehicle technology, speech video, facial recognition, text recognition and various AI services such as dialogue and interaction technology; It is indisputable that the continuous development and maturity of these technologies have brought a lot of convenience to people's life. Especially in the field of home design, the emergence of artificial intelligence has greatly improved the efficiency and quality of modern home life. People's demand for products also promotes the continuous progress and development of AI technology, so artificial intelligence will continue to change and affect our home life.

\section{Application of artificial intelligence in modern home design}

\subsection{The concept and developments smart homes}

Smart home is a system that combines all kinds of subsystems related to home life through household information management platform with computer, networks and integrated wiring technology. [2] This system has closely linked a variety of home appliances with people's home life, saving efforts, enhancing the utilization of time, and improving the comfort, safety and quality of home life. Home system design is closely combined with artificial intelligence, so that users can enjoy more effective and humanized home experience. (see table 1)

Table 1. The development of smart home in certain countries 


\begin{tabular}{|c|c|c|}
\hline $\begin{array}{c}\text { Countr } \\
y^{3}\end{array}$ & $\begin{array}{c}\text { Typical } \\
\text { Companies }\end{array}$ & Household Technology Advantage \\
\hline $\begin{array}{l}\text { United } \\
\text { States }\end{array}$ & $\begin{array}{l}\text { Amazon Echo } \\
\text { Google Home } \\
\text { Apple HomeKit } \\
\text { Contro14 }\end{array}$ & $\begin{array}{l}\text { The voice control of intelligent home } \\
\text { control system has obvious advantages } \\
\text { and can realize the interconnection } \\
\text { and communication of various devices } \\
\text { through the intelligent home center. }\end{array}$ \\
\hline U. K. & Laing Homt & $\begin{array}{l}\text { The development time is early and the } \\
\text { intelligent management system is } \\
\text { relatively complete }\end{array}$ \\
\hline $\begin{array}{c}\text { German } \\
y^{3}\end{array}$ & Apartimentum & $\begin{array}{l}\text { Future apartments combine Intemet of } \\
\text { things applications with advanced } \\
\text { technology. }\end{array}$ \\
\hline Japan & Panasonic & $\begin{array}{l}\text { Pay attention to the intelligence of } \\
\text { indoor spaces, intelligence degree is } \\
\text { higher. }\end{array}$ \\
\hline $\begin{array}{c}\text { Singap } \\
\text { ore }\end{array}$ & $\mathrm{NICO}$ & $\begin{array}{l}\text { Combined intelligence with energy } \\
\text { saving, the whole house envirorment } \\
\text { control system is relatively mature }\end{array}$ \\
\hline
\end{tabular}

Research and Markets forecast that the global smart home market will grow at an annual rate of 14 per cent over the next five years and reach $\$ 122$ bn by 2022 . It is expected to surge to $\$ 400$ bn by $2030 .{ }^{[3]}$ According to the analysis, China's smart TV penetration rate in recent years and the trend of the next two years in general is on the rise, and some more common intelligent home appliances such as smart refrigerator, smart washing machine, smart air conditioning, smart TV will also enjoy an increasing penetration rate. (see figure 1)

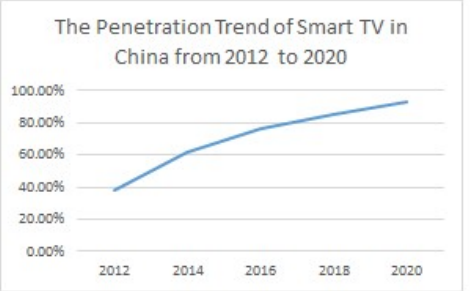

Figure 1. The Penetration Rate of Smart TV Trend

\subsection{The application of artificial intelligence in modern homes}

\subsubsection{Smart kitchen}

With the development of artificial intelligence technology, the emergence of smart kitchen has greatly improved people's happiness index.

For example, the intelligent sound box products and a whole set of intelligent kitchen products interconnect and communicate, to achieve more friendly interaction, more powerful functions and services. For example, (1) all kitchen electric intelligent products in the kitchen can achieve intelligent voice control by connecting the speakers. Moreover, the powerful interaction ability can also easily realize the complex function of kitchen appliances. (2) in intelligent kitchen, as long as the user prepares the ingredients and inputs instructions or directly use of the function of the recommended recipes, the smart systems will be instantly connected to the cloud platform, search the recipe database, and then automatically move the ingredients to the cooking devices. Reserved cooking and one-key cooking makes it time-saving and trouble-saving for the users. (3) In the future, there may be the emergence of the refrigerator that can identify the freshness of the stored food and to alert the users accordingly, by recording the date that the ingredients were stored in the fridge to remind the user, and display the best edible date, and alert the users about the expired food.

\subsubsection{Smart bedroom}

In smart bedrooms, you can give instructions to all kinds of systems to work automatically directly through your smart phone remotely. For instance:

(1) The switch of intelligent air conditioning; users are able to adjust the required room temperature in advance when they are still outside.

(2) Users can adjust to the proper indoor light according to the environment and time. Based on the room humidity level to automatically adjust to the appropriate indoor air humidity that suits the human body.

(3) Users can control their curtains and windows by wireless connections whenever and wherever possible.

(4) Some studies pointed out that normal people will turn 30 to 60 times during their sleeps. Based on the analysis of the body's dynamic movement and the date generated, the smart bed are able to adjust to the most suitable bed surface state and angle that conforms to human engineering and the user's body structure, allowing users to obtain a more suitable sleep environment. Smart beds can also monitor users' sleep and improve their sleep quality by providing a more suitable sleeping environment through computational analysis.

\subsubsection{Smart living room}

Artificial intelligence is more widely used in living rooms.

(1) Smart TV can directly switch channels via voice control. The traditional remote controls are no longer needed. The brightness sensors can detect the light level in the environment and automatically adjust the brightness and color, enhance the users' visual experience.

(2) Intelligent thermostat sensors monitor the temperature of homes. It evaluates the actual home conditions to adjust the right temperature automatically. Users can have access to the thermostat via mobile phone connections and remotely view and adjust the indoor temperature.

(3) Lamps are the indispensable part of the living room. The intelligent lamps can adjust themselves according to user's biological clock, to meet various needs of users. Users can also easily operate on the mobile phone for lamp management, in accordance with the requirements of different scenarios to adjust light feeling, building exclusive atmosphere.

(4) The highest utilized and also the most indispensable part of the living room is probably the sofa. After combining with artificial intelligence, sofa will be more powerful and functional. Equipped with electronic devices, the sofa will be safe and convenient for users. The head rest with automatic adjustment, includes 
massage function, user can obtain more comfortable experience on sofa.

(5) Through the phone APP voice control system to control the whole living room appliances, choose a different model to adjust the need of environment condition. For example, if the sleep mode is chosen, then $\mathrm{TV}$, lighting, curtain of the sitting room will be closed automatically. Intelligent electric control system can remotely control and manage the electrical appliances, the user can through electronic devices such as mobile phones, smart panel of household electrical appliances for centralized management, so as to achieve the goal of energy saving, environmental protection, and convenience. ${ }^{[4]}$

\subsubsection{Smart bathroom}

Smart bathroom is to apply artificial intelligence technology to bathroom products, providing users with a strong and efficient bathroom experience. For example:

(1) intelligent bath mirrors can well solve the mist on the ordinary mirrors in the bathroom caused by water vapor and the problem of inconvenience to users, automatic clean mirrors can display temperature and weather information, offering advice for the user dress.

(2) The intelligent bathtub can make full use of the impact of water to spray into the corresponding acupuncture points of the body according to the user's physical condition, and provide the user with a full body massage.

(3) The bathroom environment is relatively wet, so bacteria can easily grow on the towels. The intelligent towel racks are able to quickly achieve high temperature sterilization, efficient drying towels, and bring more healthy life for users.

(4) Intelligent ventilation equipment is extremely important in small spaces like the bathrooms. It can automatically control the ventilation based on the air conditions and environment temperatures, making the small space of the bathroom environment more cozy and comfortable.

\section{Disadvantages of artificial intelligence home}

\subsection{It causes emotional loss to users}

Everything has two sides. From the user's point of view, powerful features of the artificial intelligence can greatly make people's daily lives more comfortable. But to a certain extent, it could make users rely too much on machines and cause the lack of interactions. For example, the kitchen electric system activated by one-key cooking may reduce the user's enjoyment of life. Excessive dependence will also lead to a decline in the ability of users to take care of themselves in daily life, and the reduction of users' initiative may also lead to a lazy habit.

\subsection{Power system constraints}

Nowadays, to a large extent, smart homes need power to operate. If there is a power failure, their functions will be limited, which will bring inconvenience to users. And, as a smart home needs professional technology as support, in the face of failure or more urgent circumstances, it may be difficult to do self-testing and maintenance. At present, the installation, debugging and use of the intelligent home system are too complex, and the comprehensive functions are more complex, which will restrict the transformation of the intelligent home products from research and development products to consumer products. ${ }^{[5]}$

\subsection{Lack of pertinence and initiative}

Different users may have different requirements or demands. The intelligence lives in big data analysis may have a certain degree of limitations, such as kitchen cooking functions of electrical system, for different tastes of people on the choice will be difficult, all aspects may be not as good as the user's own operations, on the meet the general needs of users and can't do it in detail, and fully meet the needs of all kinds of people. Some operational smart homes require people to issue instructions before they can operate, and there's a lack of their autonomous mobility.

\section{The future of artificial intelligence in the design of modern homes}

By comparing the smart home appliances of smart kitchens in China and France, one can clearly see the differences between Chinese and western diet culture, even in the era of kitchen intelligent temperature control, Chinese people still don't like to use the electric oven, as well as kitchen scale. So smart home should pay attention to people. Different products should be developed and promoted to meet the different needs of different culture and dieting habits. Closely combine the intelligent features and everyday life. Let the user enjoy the convenience of smart homes. Therefore, we need to pay attention to the following key points.

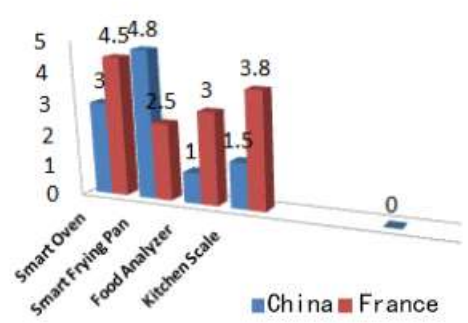

Figure 2.

Table 2.

\begin{tabular}{|l|l|}
\hline Smart Oven & $\begin{array}{l}\text { accurately control } \\
\text { the temperature }\end{array}$ \\
\hline Smart Frying Pan & $\begin{array}{l}\text { accurately control } \\
\text { the temperature }\end{array}$ \\
\hline Food Analyzer & facilitate the \\
\hline
\end{tabular}




\begin{tabular}{|l|l|}
\hline & balanced diet \\
\hline Kitchen Scale & Smart kitchen scale \\
\hline
\end{tabular}

\subsection{Intelligent design needs to be more humane}

While paying attention to technology, intelligent design should also pay attention to humanistic feelings. According to the specific situation of each family to carry out personalized customization, transform the home into the most satisfied, most comfortable conditions, which can guarantee the maximum life enjoyment.

Take Chengdu of Sichuan province as an example, locals love to relax, leisure, and enjoy life. Then in designing smart homes, one should consider more leisure entertainment functions, such as the massage-functioned smart sofa in the sitting room and the intelligent kettle that can control water temperature, etc.

And for some older people who may be more willing to return to nature and lead a leisure and comfortable life by growing vegetables and flowers. Then the intelligent garden system is important for automatically watering, controlling soil moisture and temperatures

For the pursuit of life interest, value the life attitude of the users, it should be configured to recognize play in different situation in the intelligence of music background music system, playing soothing music when get up, for the user day and bring a good mood, play to be able to concentrate when reading or work music, in the leisure entertainment, playing music can alleviate fatigue.

\subsection{The realization of personalized differentiation service of artificial intelligence}

The smart homes have become increasingly well functioned. But how to satisfy different needs of different users is a key question it needs to answer. Intelligent home design should have more tailor-made features for targeted users. More customized functions of the intelligent home design can be gradually developed based on different users' feedbacks.

Voice control system for household, for example, is likely to create communication problems due to different dialects and different phonetic system in different regions. So the phonetic system of regional settings should be more targeted, provides the users with the option of a tailor-made language system and the other option of a popular language system as the alternative means of communication, reduce unnecessary obstacles due to differences in language habits.

And people from different regions have different cuisines, which lead to the differentiated features of the smart kitchen appliances. Take China as an example, the people in north China like noodles while people in south China prefer rice; people from east China like cakes and dessert while people from southwest China prefer spicy food. Kitchen appliances, therefore, need to take these factors into consideration when they are produced for people from a designated region.

For young parents, smart homes play an important role in looking after their babies since they tend to be very busy working. The smart childbed can automatically soothe the child when he is crying, and have real-time monitor on him to prevent him from falling to the ground. A camera in a smart home system can also monitor the real-time situation for parents to observe. Parents can also use remote controls to select sleep patterns while their children are asleep, just with a single click.

The nursing system should be the most important function system for the elderly who live alone. The emergency assistance function can timely inform the family and alarm when the elderly encounter unexpected situations. Intelligent security can detect home appliances, gas, status of access control and other facilities, to ensure the safety in daily life, control is one key to elderly users to provide more convenient, worry-free of everyday life.

\subsection{Information security needed for intelligent design}

Nowadays, the rapid development of the Internet brings people convenient life, while personal information becomes more and more transparent and exposable. To prevent malicious access to users' information, it is vital to strengthen the security protection of smart home system and secure the transmission channel where users interact with smart home appliances.

\subsection{Smart homes should cater to popular, civilian consumption}

Nowadays, the price of intelligent household equipment in the market is relatively high which restricted its penetration rate. The immature technology is contributing to the high price of the systems, which leads to the narrow range of market acceptance. Fixture as each family and household, market demand is very big, so the popularity of smart home should consider the public's consumption level, the operation simple and more convenient service to expand the market, through the ascension of the technology to control the production cost, reduce consumer repeat investment; Through the perfect and convenient after-sales service to solve the problems arising from the products in use process, give full play to the powerful features of the smart home, can provide users with more convenient and comfortable daily life.

\section{Summary}

Artificial intelligence home appliances have greatly facilitated people's daily life, but everything has two sides; the development of artificial intelligence home appliances is also a double-edged sword. The development of smart homes is not aimed at completely overthrowing the old way of life. The use of the smart home brings the user's emotional loss, high cost, high technical requirements, maintenance problems such as weak pertinence and independent initiative is still there. While give users convenient life, therefore, there should be more reflection on the existing problems and better solve or avoid those problems in the future development of smart home appliances. This way smart home appliances could gain 
market advantage, and gained popularity and development.

\section{References}

1. Li huaqiang, On the Impact of Artificial Intelligence[]]. Information Recording Materials, 18, (2017)

2. Shen Hua, Current Situation and Prospect of Intelligent Home Ddevelopment [J] Information and Computer,03 (2017)
3. Rong Huaying and Lian Guowen, International Smart Home Trade Prospects in the Context of Artificial Intelligence Development [J]. Foreign Trade and Economic Practice, 10 (2017)

4. Wu Bin, Development Status, Existing Problems and Countermeasures of China's Smart Home System [J]. Wireless Internet Technology,24 (2016)

5. Zhu Minling, Li Ning, Status Quo and Future Analysis of Intelligent Home Development[]].TV Hormone,4 (2015) 